\title{
HYBRID ROUGH SET AND DATA ENVELOPMENT ANALYSIS APPROACH TO TECHNOLOGY PRIORITISATION
}

\author{
Ewa CHODAKOWSKA (D)*, Joanicjusz NAZARKO ${ }^{\text {(D) }}$ \\ Faculty of Engineering Management, Bialystok University of Technology, Bialystok, Poland
}

Received 13 October 2019; accepted 23 February 2020

\begin{abstract}
The complexity and speed of change in technological systems pose new challenges to technology management. Particular attention should be given to the issue of modelling the uncertainty of assessments and creating rules for determining the weights of the technology assessment criteria. The article aims to present a comprehensive hybrid technology prioritisation model based on the Data Envelopment Analysis and the concept of Rough Sets. The technology prioritisation process that uses the proposed model includes three consecutive stages: (i) the formulation of technology assessment matrix, (ii) the removal of the criteria redundancy based on indiscernibility relation defined in the Rough Set Theory, (iii) the development of rough variables and prioritisation using the DEA super-efficiency model. The combination of DEA and RS is a unique proposal to classify and rank objects based on the tabular representation of their conditional attributes under circumstances of uncertainty. Application of the developed hybrid model to the real data of the technology foresight project "NT FOR Podlaskie 2020" positively verified the assumed effects of its use. The obtained results allow a more objective and rational justification of the chosen technology, simplification of interpretation and better authentication of results from the perspective of decision-makers.
\end{abstract}

Keywords: Data Envelopment Analysis (DEA), Rough Sets (RS), hybrid model, technology prioritisation, technology management, technology assessment.

JEL Classification: M11, O32, C61.

\section{Introduction}

The development of the research area related to technology assessment was necessitated by the growing need to support the currently existing decision-making processes and actively shape them as desired for the future while developing a scientifically-based technology strategy. In line with growing attention that is given to sustainability development in policymaking (Zavadskas et al., 2019), great interest is observed in procedures and practices aimed at directing the future technical-social change under conditions of uncertainty and complexity (Weber et al., 2019).

\footnotetext{
${ }^{\star}$ Corresponding author. E-mail: e.chodakowska@pb.edu.pl
} 
A comprehensive, multidimensional analysis of advanced, interrelated technologies in the face of social, economic and environmental challenges such as, for example, increasing energy needs, social inequalities, growing global population (Nazarko, 2015), aging (Ejdys \& Halicka, 2018), is a difficult task, but necessary to successfully manage technologies. The importance of the problem and its interdisciplinary nature were reflected in the development of very different approaches, methods and tools for technology assessment. In the literature, prioritisation is treated as an independent method or an element of complex models used for technology assessment. The aim of technology prioritisation is the unequivocal indication of key strategic technologies with great potential to contribute to economic development, to build a long-term competitive advantage, at the same time satisfying social needs and preserving the environment while having in mind limited investment funds and, therefore, rationally allocating resources (Chodakowska, 2019).

Technology prioritisation, like technology assessment, is permanently associated with uncertainty. The necessity to consider uncertainty particularly concerns the assessment of new or emerging technologies due to inaccurate or vague data, the inability to assess all consequences arising from the interaction between the technology, the environment and the society, the reliance on knowledge and subjective expert opinions. The addressed research problem concerned the possibility to use the hybrid model combining the Data Envelopment Analysis (DEA) by Charnes, Cooper and Rhodes (1978) and Rough Set (RS) Theory by Pawlak (1982) methods in the process of technology prioritisation. The main issue solved was to determine the integration procedure to exploit the potential of methods and increase the objectivity of technology assessment under conditions of uncertainty. The originality and innovation of the approach is based on the design of integration of RS and DEA in a model that hasn't been reported in the literature so far. It is a new proposal for technology assessment that addresses the need for multifaceted and objective assessment modelling the vague valuation of criteria by individual experts.

The article consists of a brief background literature review introducing and regarding the previous research on the subject. The second part of the article presents the methodological framework: DEA and the concept of Rough Sets. Then, the RS-DEA model for technology prioritisation is developed and discussed supported with a case study. The article finishes with conclusions.

\section{Background literature}

\subsection{Technology prioritisation in technology assessment}

The development of technology assessment is associated with projects carried out in the late 1950s on forecasting the development of technology and their consequences. The concept of technology assessment itself, attributed to Daddario, was formulated in the late 1960s in the United States as the name used by the US Congress for researching and shaping policy towards technological innovations as well as supporting technology management and control (Porter, 1995; Nazarko, 2015).

Later, Decker and Ladikas (2004) described technology assessment as a scientific, interactive, and communicative process which aims to contribute to the formation of public and po- 
litical opinion on societal aspects of science and technology. Related to technology assessment is the concept of science and technology studies (either: science, technology and society studies) - STS, which can be defined as a field of interdisciplinary, heterogeneous research on the relationship between scientific knowledge, technology systems and society using research methods, primarily sociology, anthropology, philosophy (Roosth \& Silbey, 2009). In addition to the technology assessment (TA) in the field of future technology management, technology foresight (TF) and technology forecasting have been developed, both of which are included in the concept of future-oriented technology assessment (FTA) (Cagnin et al., 2013; Halicka, 2016; Nazarko, 2015).

Recalling the most popular definitions in short, TF is a process involved in systematically attempting to look into the longer-term future of science, technology, the economy and society with the aim of identifying the areas of strategic research and the emerging generic technologies likely to yield the greatest economic and social benefits (Martin, 1995). Łunarski (2009) summarised technology forecasting as a formulation of anticipated directions of technology development and technological progress. FTA comprises technology forecasting, technology foresight, and technology assessment to analyse the future of technologies and their consequences for effective management of technology. FTA allows to assess the current state of technology, to identify factors conducive to its development, to examine the impact of technology on the environment and the impact of the environment on technology, and also to predict the future of the development of implemented and emerging technologies (Porter et al., 2004). FTA tools enable systematic assessment of potential challenges, opportunities and threats to formulate long-term strategies (Sánchez-Torres \& Miles, 2017). Discussions of differences between the approaches are subjects of works, by inter alia Halicka (2016), Łunarski (2009), Martin (2010), Miles (2008), Nazarko (2017). Indisputable is the acceptance of the importance and increasing need within technology assessment for effective technology management from the perspective of future in the public services sector (Sokolov et al., 2019; Sánchez-Torres \& Miles, 2017) and private corporations (Pietrobelli \& Puppato, 2016; Rohrbeck \& Gemünden, 2011).

The methods and techniques which fit into the field of TFA have been the subject of many scientific typologies and classifications (see: Aaltonen \& Sanders, 2006; Cuhls et al., 2002; Gordon \& Glenn, 2004; J. E. Karlsen \& H. Karlsen, 2013; Magruk, 2011; Miles \& Keenan, 2003; Popper, 2008; Popper \& Korte, 2004; Porter, 2010; Voros, 2006). The analysed methods and concepts are complementary and compensate for their limitations, or duplicate tasks through triangulation, ensuring higher quality research. The considered methods are original propositions or are only derivatives of other previously developed models. Despite the experience of using common methods, it is always worth exploring new methods of using information resources and a new approach to complex systems to broaden the perspective and authenticate the results (Porter et al., 2004).

Prioritisation in technology assessment methods can take the form of a sorted list - a ranking or classification with grades according to selected criteria - rating. A review of over 1,000 foresight studies by Popper (2009) has identified 25 methods as the most commonly used: morphological analysis, swot analysis, multi-criteria analysis, cross-impact/structural analysis, bibliometrics, brainstorming, relevance trees, trend extrapolation/megatrends, 
essays, gaming, role-playing, key technologies, stakeholder mapping, technology roadmapping, Delphi, modelling and simulation, experts panels, citizens panels, backcasting, literature review, scenarios, environmental scanning, questionnaire/survey, workshops, interviews. Among them, prioritisation methods of multi-criteria analysis and key technologies can be considered.

Multi-criteria analysis (Multiple Criteria Decision Making - MCDM) is a large group of decision support methods. According to Greco, Matarazzo, and Słowiński (2001), the basic distinction divides methods into: functional, based on multi-attribute utility theory developed by Keeney and Raiffa (1976), and relational, represented in the form of an outranking relation by Roy (1991) or a fuzzy relation by Fodor and Roubens (1994). Recent developments with an overview of MCDM model taxonomies was by presented Zavadskas and Turskis (2011).

The key technologies method used in technology assessment projects is not a specific calculation procedure either. The implementation of the key technology method, which means the identification of the most important ones, in the case of multi-faceted assessment involves the use of some multi-criteria analysis technique. The typical approach is only two-dimensional assessment with conventional functions of attractiveness - aggregating socioeconomic benefits, scientific and technical opportunities generated by technologies and feasibility - i.e. the sum of the possibilities of technology implementation, its research and technological potential and the potential to absorb socioeconomic benefits (Nazarko \& Magruk, 2013). Analysed dimensions are attractiveness and the impact on competitive position (Durand, 2003), significance and feasibility or the impact and feasibility. In general, the determination of the role can be done on any two-dimensional surface from the assumed aim perspective, e.g. by drawing the influence-dependence chart (Ejdys et al., 2016).

The DEA by Charnes, Cooper, and Rhodes (1978), proposed in the hybrid technology prioritisation model, is sometimes indicated as an MCDM technique (Papagapiou et al., 1997; Doyle \& Green, 1993). The relations between DEA \& MCDM were discussed, among others, by Belton and Vickers (1993), Stewart (1996), Opricovic and Tzeng (2003). DEA is included in the group of multi-criteria analysis methods, using a specific utility function with a weighted sum of grades defined by empirical reference points. The technology assessment using the DEA method is an analysis of its value expressed by the relation of the weighted sum of technology functionalities to the weighted sum of costs in relation to the assessment of alternative technologies.

Regardless of the method of technology assessment, it is always associated with uncertainty (Magruk, 2017). Since the basis for technology assessment is expert knowledge, it is equivalent to the inclusion of subjective and uncertain information for analysis. The sources of uncertainty are inaccurate or incomplete or unreliable data characterising the technology, the inability to predict and estimate all the consequences of technology development or even the possible lack of impartiality of experts (Chodakowska, 2019).

Many methods established to deal with the information uncertainty postulate the incorporation of the quantitative degree of uncertainty that allows the formalisation of reasoning and effective management of uncertainty. One of the most popular approaches to modelling uncertainty is Zadeh's (1965) Fuzzy Set Theory and its further developments in the form 
of, for example, Interval-Valued Fuzzy Sets (Sambuc, 1975) and Intuitionistic Fuzzy Sets (Atanassov, 1983; Atanassov, 2017). Examples of approaches based on other assumptions are Soft Set Theory (Molodtsov, 1999) and Grey Set Theory (Ju-Long, 1982).

Included into the hybrid model Rough Sets were originally developed to deal with inconsistency problems of information granulations arising from a vague description of objects. In technology prioritisation hybrid model, the techniques of Rough Set Theory were used at two stages of analysis: to remove the criteria redundancy and to model uncertainty in expert opinions.

\subsection{RS and DEA in technology assessment}

A literature review of state of the art in Rough Sets in technology assessment indicates that Rough Sets are mainly used as data mining technology tools. The basic applications of RS are reducing and eliminating redundancies in data sets, discovering relationships between objects, attributes and generating decision rules, assigning weights to attributes based on their significance and modelling linguistic uncertainty.

As a tool to reduce the number of assessment criteria, RS was used by Wu and Lin (2012), who identified key factors affecting the quality of e-learning services. Ciflikli and Kahya-Ozyirmidokuz (2012) documented the successful reduction in the number of variables considered in the quality control in production. Similarly, to eliminate correlations between attributes and increase data precision, RS concepts were used by Wang, Jia, and Wang (2015) in assessing the efficiency of coal technologies. Sharma, Dua, Singh, Kumar, and Prakash (2018) used Fuzzy Rough Sets in eliminating the problem of data imprecision and improving the efficiency of real-time calculations in energy management systems. An additional application of RS was the generation of decision rules in the case of unexpected, unclear situations.

Only in the function of decision rules induction, the RS theory utilised work by Wang, Chin, and Tzeng (2010) to find principles in R\&D and innovation activity of high-tech enterprises. Jian, Liu, and Liu (2010) extracted rules for decision-makers when selecting key regional technologies. The problem solved by Hemert and Nijkamp (2010) with the use of RS was the evaluation of the role of support systems and public interventions in stimulating innovative initiatives and their impact on industry efficiency and competitiveness. Shiau and Chuen-Yu (2016) assessed the impact of a wind farm on a community. Liang and Dijk (2016) used RS to analyse technological and non-technological factors in the rainwater collection system.

Considering the use of RS in determining weights, C. Lee, H. Lee, Seol, and Park (2012) determined the ranges of scores in the AHP method when assessing the concept of new services (video games). Luo and $\mathrm{Hu}$ (2015) based on the weights of attributes determined via the RS theory, proposed a model for assessing the risk of technological innovation in agricultural cooperatives. Lai, Liu, and Georgiev (2016) developed a framework for assessing the low-carbon technology integration from a management perspective, using RS to determine index weights in the model. Bai and Sarkis (2017) presented a multi-criteria model for the assessment and selection of environmentally friendly production technology using the weight values of criteria defined by RS and grey statistics. In their work, He, Pang, Zhang, Jiao, and 
Chen (2018), used the concept of RS to determine the weights in the system of indicators to assess the level of development of selected countries in the field of clean energy.

An example of RS in modelling language uncertainty in the field of technology assessment is provided in work by Zeng et al. (2016) concerning the management of a regional ecosystem.

The DEA applications in the technology analysis so far mainly concern the assessment of the eco-efficiency of technologies. The concept of environmental DEA is based on the inclusion of model variables whose increase in value is undesirable and at the same time impossible to eliminate (Chodakowska \& Nazarko, 2017a). This advantage was used by, e.g., Fan, Zhang, Zhang and Peng (2015) while analysing $\mathrm{CO}_{2}$ utilisation technologies. The level of $\mathrm{CO}_{2}$ emissions was the subject of interest in research conducted by Kwon, Cho, and Sohn (2017) who assessed energy production from renewable sources in European countries. Sueyoshi and Goto (2014) analysed the environmental impact of technological innovations in the Japanese industrial sector. Other examples are eco-efficiency of water systems in China by Liu, Sun, and Xu (2013) or environmentally friendly technologies of cooling towers in power plants by Shabani, Saen, and Torabipour (2014).

Other identified areas of DEA applications are technology selection and technology forecasting mainly with the TFDEA model introduced by Anderson, Hollingsworth and Inman (2001). The examples of the selection between existing technologies can be found in work by Amin and Emrouznejad (2013) who described choice-making of robots or research carried out by Yu and Lee (2013) on emerging nanotechnologies. One of the recent works using the TFDEA model is forecasting changes in smartphones (Srivastava \& Misra, 2016) or hybrid cars (Lim et al., 2015).

The cited studies emphasised the validity and usefulness of applying both DEA and RS. In the literature, the combination of Rough Sets with the DEA method is relatively unpopular and rarely used. The integrated approach was applied in forecasting business failures (Shuai \& Li, 2005), supply chain performance (Xu et al., 2009), and the Japanese banking sector (Shiraz et al., 2016). The assessment of new technologies in the context of FTA by DEA and RS methods is still underexploited in relation to their capabilities.

\section{Methodological framework}

\subsection{Data envelopment analysis}

The idea of DEA came from Farrell's (1959) concept of efficiency. He proposed a measure of efficiency by referencing a unit's performance (described by inputs and outputs) to the production frontier or cost frontier of fully efficient, best-performing units. DEA to calculate the efficiency involves the linear programming to build the piecewise surface frontier over the data (Figure 1).

DEA accounts for multiple inputs and outputs using the available panel data. It means that DEA evaluates technologies regarding potential benefits in relation to expenditure of implementation/development based on a weighted sum of criteria. The weights are optimally selected for each technology being assessed to maximise its score using linear programming algorithms. The final scores, specified in equation (1) as $\theta$, range from 0 to 1 . 


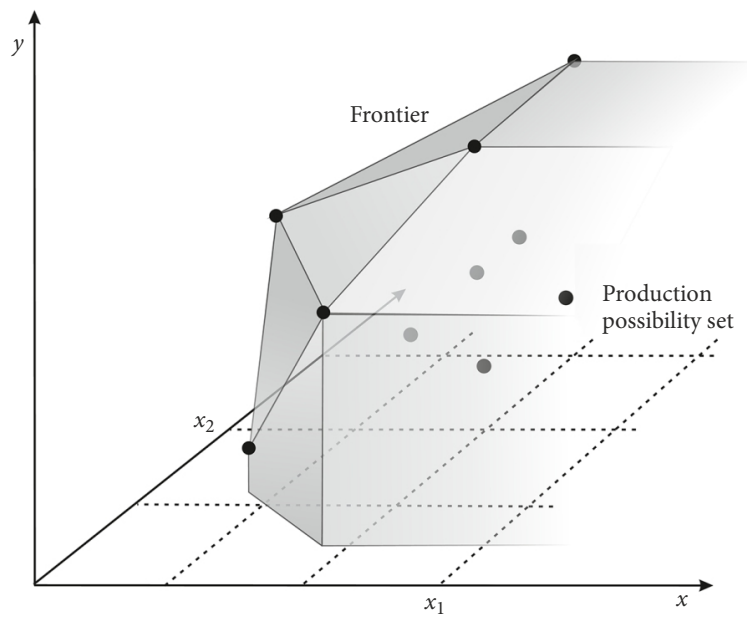

Figure 1. DEA concept

The linear programming problem for object $j$, cost criteria vector: $X_{j}=\left(x_{j 1}, x_{j 2}, \ldots, x_{j m}\right.$, $\left.\ldots, x_{j M}\right)$ and benefit criteria vector: $Y_{j}=\left(y_{j 1}, y_{j 2}, \ldots, y_{j s}, \ldots, y_{j S}\right)$ is defined as follows:

$$
\begin{aligned}
& \min \theta, \\
& \sum_{j=1}^{n} \lambda_{j} x_{j m} \leq \theta x_{j_{O} m}, m=1, \ldots, M, \\
& \sum_{j=1}^{n} \lambda_{j} y_{j s} \geq y_{j_{O} s}, \quad s=1, \ldots, S, \\
& \lambda_{j} \geq 0, j=1, \ldots, n .
\end{aligned}
$$

The symbol $\lambda_{j}$ represents the vector of weights specifying the intensity of the use of reference technologies characteristics in the optimal solution for technology.

Since its introduction, the basic DEA (1) model, called CCR (Charnes et al., 1978), has been supplemented and modified for non-constant return to scale analysis (BCC, hybrid return-to-scale models) or to include the peer-evaluation (cross-efficiency models, cross-efficiency profiling). An interesting extension is network DEA models that allow the assessment of multi-stage processes (Chodakowska \& Nazarko, 2017b). From the point of view of the use of DEA for technology prioritisation, it seems justified to use super-efficiency models (SE-DEA) that provide discrimination among efficient technologies because they do not limit the maximum result to 1 .

From DEA features and analytical capacities, the RS-DEA hybrid approach employed SEDEA linear programming task to determine the weight of criteria and the DEA definition of efficiency to create the synthetic assessment. 


\subsection{Rough sets}

The Rough Set Theory, introduced by Pawlak (1982), is a mathematical approach to vagueness and uncertainty. The RS approach hinges on the concept of lower and upper approximations of a set (Figure 2).

The Rough Set Theory is founded on the assumption that each object $t$ in non-empty, finite set $U$ is associated with some information - attributes $a(t)$. An object characterised by the same values of attributes is indiscernible, given the available information (Pawlak \& Skowron, 2007). The indiscernibility relation allows identifying objects with the same properties that can be treated as identical or similar. This relation on the set of technology $U$, and the subset of attributes (criteria) $B$, for $B \subseteq A$, is defined as:

$$
\operatorname{IND}(B)=\left\{\left(t, t^{\prime}\right) \epsilon U^{2}: \underset{a \in B}{\wedge} a(t)=a\left(t^{\prime}\right)\right\} .
$$

The attribute $a$ is dispensable (dependent) in $C \subseteq A$, and $a \subseteq C$ is true:

$$
\operatorname{IND}(C)=\operatorname{IND}(C-\{a\}) .
$$

A set of attributes $B$ is indispensable (independent) if, for each $a \subseteq B$, a is indispensable. The set $B \subseteq A$ is called the reduct $-\operatorname{RED}(B)$, if $B$ is independent in $A$ and $\operatorname{IND}(B)=\operatorname{IND}(A)$. The CORE is the set that consists of those attributes which are members of all reducts (intersection of reducts):

$$
\operatorname{CORE}(B)=\cap R E D(B) .
$$

The hybrid RS-DEA model uses the idea of reducts to limit the number of criteria and the approximation of the set to deal with uncertain values characterising technology.

The hybrid model adopts the concept of rough variable $\xi$ (Liu, 2004) to include uncertainty:

$$
\xi=([a, b],[c, d]), \text { for } c \leq a<b \leq d .
$$

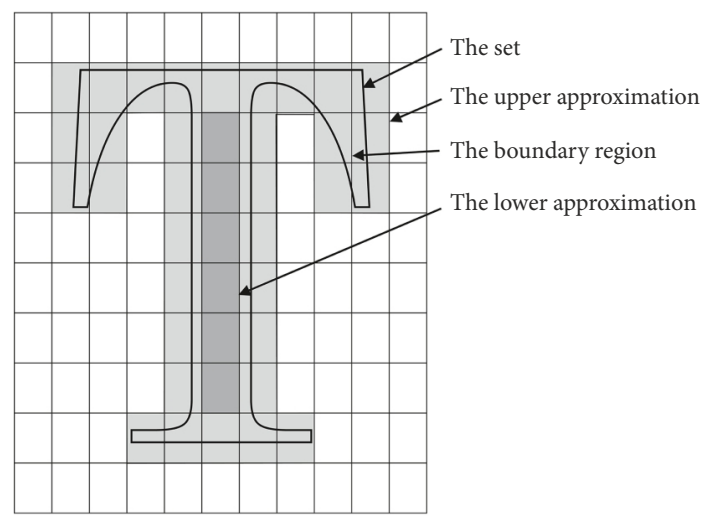

Figure 2. Rough set 
For the given rough variable $\xi$ and $\alpha \in(0,1]$, the $\alpha$-optimistic value and $\alpha$-pessimistic value could be defined as (Tohidi \& Valizadeh, 2011):

$$
\begin{aligned}
& \xi^{\sup (\alpha)}=\left\{\begin{array}{c}
(1-2 \alpha) d+2 \alpha c, \quad \text { if } 0 \leq \alpha \leq \frac{d-b}{2(d-c)} \\
2(1-\alpha) d+(2 \alpha-1) c, \quad \text { if } \frac{2 d-a-c}{2(d-c)} \leq \alpha \leq 1 \\
\frac{d(b-a)+b(d-c)-2 \alpha(b-a)(d-c)}{(b-a)+(d-c)}, \text { otherwise }
\end{array} ;\right. \\
& \xi^{\inf (\alpha)}=\left\{\begin{array}{c}
(1-2 \alpha) c+2 \alpha d, \quad \text { if } 0 \leq \alpha \leq \frac{a-c}{2(d-c)} \\
2(1-\alpha) c+(2 \alpha-1) d, \quad \text { if } \frac{b+d-2 c}{2(d-c)} \leq \alpha \leq 1 \\
\frac{c(b-a)+a(d-c)-2 \alpha(b-a)(d-c)}{(b-a)+(d-c)}, \text { otherwise }
\end{array} .\right.
\end{aligned}
$$

Using the dependencies is the possibility of converting the approximate variable into the range: $\left[\xi_{\text {sup }}(\alpha), \xi_{\text {inf }}(\alpha)\right]$ for $0.5 \leq \alpha \leq 1$ and $\left[\xi_{\text {inf }}(\alpha), \xi_{\text {sup }}(\alpha)\right]$ for $0<\alpha \leq 0.5$.

The presented relationships are used in the construction of the hybrid model to consider inconsistencies and contradictions of expert assessments.

\section{Development of an RS-DEA model for technology assessment}

Using the hybrid model, the technology prioritisation process assumes the implementation of standard first stages of technology assessment projects: the definition of study objectives and the definition of a list of assessment criteria and technologies.

The hybrid model of technology prioritisation is applied to a filled matrix of data on technologies, the rows containing the values of individual technology assessment in terms of criteria defined in the columns:

$$
\left[\begin{array}{ccccccccc}
x_{11} & x_{12} & x_{13} & \ldots & x_{1 M^{*}} & y_{11} & y_{12} & \ldots & y_{1 S^{*}} \\
x_{21} & x_{22} & x_{23} & \ldots & x_{2 M^{*}} & y_{21} & y_{22} & \ldots & y_{2 S^{*}} \\
x_{31} & x_{32} & x_{33} & \ldots & x_{3 M^{*}} & y_{31} & y_{32} & \ldots & y_{3 S^{*}} \\
x_{41} & x_{42} & x_{43} & \ldots & x_{4 M^{*}} & y_{41} & y_{42} & \ldots & y_{4 S^{*}} \\
x_{51} & x_{52} & x_{53} & \ldots & x_{5 M^{*}} & y_{51} & y_{52} & \ldots & y_{5 S^{*}} \\
\ldots & \ldots & \ldots & \ldots & \ldots & \ldots & \ldots & \ldots & \ldots \\
x_{j 1} & x_{j 2} & x_{j 3} & \ldots & x_{j M^{*}} & y_{j 1} & y_{j 2} & \ldots & y_{j S^{*}} \\
\ldots & \ldots & \ldots & \ldots & \ldots & \ldots & \ldots & \ldots & \ldots \\
x_{n 1} & x_{n 2} & x_{n 3} & \ldots & x_{n M^{*}} & y_{n 1} & y_{n 2} & \ldots & y_{n S^{*}}
\end{array}\right]
$$

where: $\left[\begin{array}{llllll}x_{j 1} & x_{j 2} & \ldots & x_{j m} & \ldots & x_{j M^{*}}\end{array}\right]$ - the input vector of criteria describing the cost of technology development/application; $\left[\begin{array}{llllll}y_{j 1} & y_{j 2} & \ldots & y_{j m} & \ldots & y_{j S^{*}}\end{array}\right]$ - the output vector 
criteria describing the benefits of technology development/application; $n$ - the number of technologies considered, $j=1,2, \ldots, n ; M^{*}-$ the original number of input criteria; $S^{*}-$ the original number of output criteria.

The matrix is a Rough Set system $S I=\{U, A\}$, where $U$ - a universe, non-empty set of objects (technologies): $U=\left\{t_{1}, t_{2}, \ldots, t_{n}\right\}, A-$ a non-empty set of attributes (criteria): $A=\left\{a_{1}, a_{2}, \ldots, a_{M^{*}}, a_{1}, a_{2}, \ldots, a_{S^{*}}\right\}$.

In the hybrid model, it is proposed to employ indiscernibility relation defined in the Rough Set Theory and the concept of reducts to limit the number of considered criteria and eliminate redundancy. That way, keeping the distinction between technologies in the set, the interpretation of the final assessment is simplified.

The reduced matrix has a reduced number of inputs $M, M \leq M^{*}$ and the reduced number of outputs $S, S \leq S^{*}$. The reduced matrix is the basis for modelling vague linguistic terms and/or inconsistencies in assessments via rough variables of inputs and outputs: $\left[x_{m j}^{a}, x_{m j}^{b}\right],\left[x_{m j}^{c}, x_{m j}^{d}\right],\left[y_{s j}^{a}, y_{s j}^{b}\right],\left[y_{s j}^{c}, y_{s j}^{d}\right]$, where: $x_{m j}^{c} \leq x_{m j}^{a}<x_{m j}^{b} \leq x_{m j}^{d}, y_{s j}^{c} \leq y_{s j}^{a}<y_{s j}^{b} \leq y_{s j}^{d}$, $m=1, \ldots, M, s=1, \ldots, S$.

Using the concept of rough variables and the given level $\alpha$, such as $0.5 \leq \alpha \leq 1$, $\alpha$-optimistic and $\alpha$-pessimistic values are calculated for each criterion and each technology: $\left[x_{j m}^{\sup (\alpha)}, x_{j m}^{\inf (\alpha)}\right],\left[y_{j s}^{\sup (\alpha)}, y_{j s}^{\inf (\alpha)}\right]$. The following (9)-(12) formulas based on (6)-(7) are employed:

$$
x_{j m}^{s u p(\alpha)}\left\{\begin{array}{l}
(1-2 \alpha) x_{m j}^{d}+2 \alpha x_{m j}^{c}, \quad \text { if } 0 \leq \alpha \leq \frac{x_{m j}^{d}-x_{m j}^{b}}{2\left(x_{m j}^{d}-x_{m j}^{c}\right)} \\
2(1-\alpha) x_{m j}^{d}+(2 \alpha-1) x_{m j}^{c}, \quad \text { if } \frac{2 d-x_{m j}^{a}-x_{m j}^{c}}{2\left(x_{m j}^{d}-x_{m j}^{c}\right)} \leq \alpha \leq 1 \\
x_{m j}^{d}\left(x_{m j}^{b}-x_{m j}^{a}\right)+x_{m j}^{b}\left(x_{m j}^{d}-x_{m j}^{c}\right)-2 \alpha\left(x_{m j}^{b}-x_{m j}^{a}\right)\left(x_{m j}^{d}-x_{m j}^{c}\right) \\
\left(x_{m j}^{b}-x_{m j}^{a}\right)+\left(x_{m j}^{d}-x_{m j}^{c}\right)
\end{array},\right. \text { otherwise }
$$




$$
x_{j m}^{s u p(\alpha)}\left\{\begin{array} { l } 
{ ( 1 - 2 \alpha ) y _ { s j } ^ { d } + 2 \alpha y _ { s j } ^ { c } , \quad \text { if } 0 \leq \alpha \leq \frac { y _ { s j } ^ { d } - y _ { s j } ^ { b } } { 2 ( y _ { s j } ^ { d } - y _ { s j } ^ { c } ) } } \\
{ 2 ( 1 - \alpha ) y _ { s j } ^ { d } + ( 2 \alpha - 1 ) y _ { s j } ^ { c } , \quad \text { if } \frac { 2 y _ { s j } ^ { d } - y _ { s j } ^ { a } - y _ { s j } ^ { c } } { 2 ( y _ { s j } ^ { d } - y _ { s j } ^ { c } ) } \leq \alpha \leq 1 } \\
{ d ( b - y _ { s j } ^ { a } ) + y _ { s j } ^ { b } ( y _ { s j } ^ { d } - y _ { s j } ^ { c } ) - 2 \alpha ( y _ { s j } ^ { b } - y _ { s j } ^ { a } ) ( y _ { s j } ^ { d } - y _ { s j } ^ { c } ) } \\
{ ( y _ { s j } ^ { b } - y _ { s j } ^ { a } ) + ( y _ { s j } ^ { d } - y _ { s j } ^ { c } ) }
\end{array} , \quad \text { otherwise } x _ { j s } ^ { i n f ( \alpha ) } \left\{\begin{array}{l}
(1-2 \alpha) y_{s j}^{c}+2 \alpha y_{s j}^{d}, \quad \text { if } 0 \leq \alpha \leq \frac{y_{s j}^{a}-y_{s j}^{c}}{2\left(y_{s j}^{d}-y_{s j}^{c}\right)} \\
2(1-\alpha) y_{s j}^{c}+(2 \alpha-1) y_{s j}^{d}, \quad \text { if } \frac{y_{s j}^{b}+y_{s j}^{d}-2 y_{s j}^{c}}{2\left(y_{s j}^{d}-y_{s j}^{c}\right)} \leq \alpha \leq 1 \\
y_{s j}^{c}\left(y_{s j}^{b}-y_{s j}^{a}\right)+y_{s j}^{a}\left(y_{s j}^{d}-y_{s j}^{c}\right)-2 \alpha\left(y_{s j}^{b}-y_{s j}^{a}\right)\left(y_{s j}^{d}-y_{s j}^{c}\right) \\
\left(y_{s j}^{b}-y_{s j}^{a}\right)+\left(y_{s j}^{d}-y_{s j}^{c}\right)
\end{array},\right.\right. \text { otherwise }
$$

To prioritise technology, the linear programming problem of the super-efficiency DEA (SE-DEA) model is solved:

$$
\begin{aligned}
& \min \theta^{\sup (\alpha)}, \\
& \sum_{j=1, j \neq j_{O}}^{n} \lambda_{j} x_{j m}^{\sup (\alpha)}+\lambda_{j_{O}} x_{j_{O} m}^{i n f(\alpha)} \leq \theta^{\sup (\alpha)} x_{j_{O} m}^{\inf (\alpha)}, m=1, \ldots, M, \\
& \sum_{j=1, j \neq j_{O}}^{n} \lambda_{j} y_{j s}^{\inf (\alpha)}+\lambda_{j_{O}} y_{j_{O} s}^{\sup (\alpha)} \geq y_{j_{O} s}^{\sup (\alpha)}, s=1, \ldots, S, \\
& \lambda_{j} \geq 0, j=1, \ldots n \text {; } \\
& \min \theta^{\inf (\alpha)}, \\
& \sum_{j=1, j \neq j_{O}}^{n} \lambda_{j} x_{j m}^{\inf (\alpha)}+\lambda_{j_{O}} x_{j_{O} m}^{\sup (\alpha)} \leq \theta^{\inf (\alpha)} x_{j_{O} m}^{\sup (\alpha)}, m=1, \ldots, M, \\
& \sum_{j=1, j \neq j_{O}}^{n} \lambda_{j} y_{j s}^{\sup (\alpha)}+\lambda_{j_{O}} y_{j_{O} s}^{\inf (\alpha)} \geq y_{j_{O} s}^{\inf (\alpha)}, s=1, \ldots, S, \\
& \lambda_{j} \geq 0, j=1, \ldots n .
\end{aligned}
$$

The use of the model results in the range of efficiency indicators for the assumed level of $\alpha:\left[\theta^{\sup (\alpha)}, \theta^{\inf (\alpha)}\right]$ for each technology. 
To sum up, the assessment process using a hybrid model includes three consecutive stages: (i) the formulation of technology assessment matrix, (ii) the removal of the criteria redundancy based on indiscernibility relation defined in the Rough Set theory, (iii) the development of rough variables and prioritisation using the DEA super-efficiency model. The result of the model application is the ranges of assessment for each technology: the maximal - optimistic and minimal - pessimistic. The scheme of technology prioritisation process using a hybrid model is presented in Figure 3.

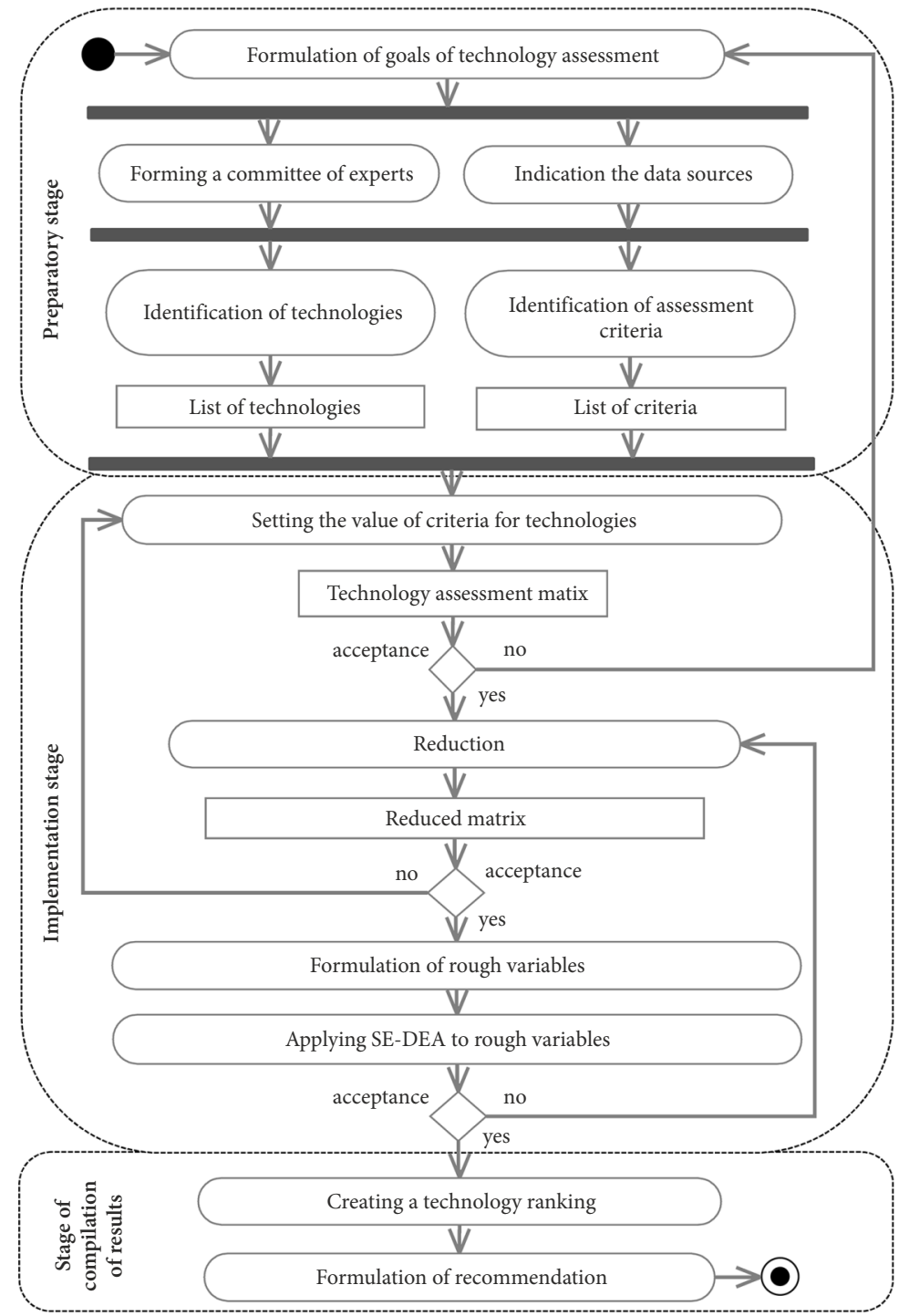

Figure 3. Diagram of the technology prioritisation process using a hybrid model 


\section{Case study}

The model was tested on data from a foresight project "NT FOR Podlaskie 2020" Regional Strategy of Nanotechnology Development. The project was implemented in 2009-2013, in an attempt to construct a scenario of the desired socio-economic development of the Podlaskie Voivodeship by identifying key priority nanotechnologies, among other things. The selection of nanotechnology was made in seven areas, fundamental for the Voivodeship, namely, wood industry, medicine, clothing industry, construction, agriculture and food industry, machine industry and transport, environmental protection, and others. The research methodology assumed the creation of a priority nanotechnology catalogue form originally 57 considered, using the key technologies method based on average values of attractiveness and feasibility criteria (Nazarko \& Magruk, 2013). The lists of criteria are presented in Tables 1 and 2.

Table 1. Attractiveness criteria considered in 'NT FOR Podlaskie 2020'

\begin{tabular}{|l|l|}
\hline & \multicolumn{1}{|c|}{ Criteria } \\
\hline A1 & The impact of technology development on the region's investment attractiveness \\
\hline A2 & The impact of technology development on the increase in private investments in R\&D \\
\hline A3 & The impact of technology development on the level of R\&D in the region \\
\hline A4 & Easy commercialisation capability \\
\hline A5 & The opportunity to use the scientific, equipment and industrial potentials of the region \\
\hline A6 & Competitiveness of technologies in relation to available solutions (patents) \\
\hline A7 & $\begin{array}{l}\text { The impact of technology development on the possibility of creating a strong competitive } \\
\text { position of regional enterprises }\end{array}$ \\
\hline A8 & The impact of technology development on the creation of new jobs \\
\hline A9 & Economic efficiency \\
\hline A10 & Boosting entrepreneurship, including SMEs, spin-offs or start-ups \\
\hline A11 & The probability of technology absorption by the existing industry in Podlaskie \\
\hline A12 & The possibility of wide dissemination and the use of results \\
\hline A13 & The probability of technology absorption by newly created industries \\
\hline
\end{tabular}

Table 2. Feasibility criteria considered in 'NT FOR Podlaskie 2020'

\begin{tabular}{|c|l|}
\hline & \\
\hline F1 & Access to funds to facilitate the implementation of technology \\
\hline F2 & Financial feasibility of technology implementation \\
\hline F3 & Technical and implementation feasibility \\
\hline F4 & The quality of human resources in the industry \\
\hline F5 & Availability of qualified staff \\
\hline F6 & The necessary research and development infrastructure \\
\hline F7 & Financial feasibility of technology implementation \\
\hline F8 & The ability to manufacture/purchase the required technical and technological equipment \\
\hline
\end{tabular}


The implementation of the hybrid RS-DEA model began with the reduction of technology data matrix determined by expert responses weighted by their declared knowledge. The process was carried out in sub-sets of feasibility (inputs) and attractiveness (outputs) with the aid of ROSE 2 - a program written at the Poznan University of Technology (Predki et al., 1998).

The results of three methods of discretisation were analysed (Table 3 ) and the most limited sets of attributes consisting of the cores of the original sets and at the same time consisting of the most frequently repeating attributes in reducts were selected. This led to the following sets of criteria for attractiveness and feasibility: $\operatorname{CORE}(B)=\left\{A_{1}, A_{2}, A_{3}, A_{9}\right\}$ and $\operatorname{CORE}(B)=\left\{F_{1}, F_{2}, F_{3}, F_{7}\right\}$.

Table 3. Core identification

\begin{tabular}{|l|c|c|c|}
\hline & Local discretisation & Local discretisation to the set $\{0,1,2\}$ & Global discretisation \\
\hline \multicolumn{5}{|c|}{ Attractiveness } \\
\hline CORE & $\{\mathrm{A} 2\}$ & - & $\{\mathrm{A} 1, \mathrm{~A} 2, \mathrm{~A} 3, \mathrm{~A} 9\}$ \\
\hline RED & 14 different reducts & 104 different reducts & $\{\mathrm{A} 1, \mathrm{~A} 2, \mathrm{~A} 3, \mathrm{~A} 9\}$ \\
\hline \multicolumn{5}{|c|}{ Feasibility } \\
\hline CORE & $\{\mathrm{F} 1, \mathrm{~F} 2, \mathrm{~F} 5, \mathrm{~F} 7\}$ & $\{\mathrm{F} 1, \mathrm{~F} 3, \mathrm{~F} 5, \mathrm{~F} 6, \mathrm{~F} 7\}$ & $\{\mathrm{F} 1, \mathrm{~F} 2, \mathrm{~F} 3, \mathrm{~F} 7\}$ \\
\hline RED & $\begin{array}{l}\{\mathrm{F} 1, \mathrm{~F} 2, \mathrm{~F} 5, \mathrm{~F} 7, \mathrm{~F} 8\} \\
\{\mathrm{F} 1, \mathrm{~F} 2, \mathrm{~F} 3, \mathrm{~F} 5, \mathrm{~F} 7\}\end{array}$ & $\{\mathrm{F} 1, \mathrm{~F} 3, \mathrm{~F} 5, \mathrm{~F} 6, \mathrm{~F} 7\}$ & $\{\mathrm{F} 1, \mathrm{~F} 2, \mathrm{~F} 3, \mathrm{~F} 7\}$ \\
\end{tabular}

Next, rough variables that account for expert assessments inconsistencies using the nominal dispersion index $h$ were formulated. Arbitrary $\pm 20 \% h$ and $\pm 10 \% h$ were assumed to design the lower and upper approximations of each criteria values. The technology scores were calculated using the SE-DEA model for and $\alpha=0.6$ and $\alpha=0.8$ and the results obtained are shown in Figure 4.

The application positively verified the assumed effects of the use of the RS-DEA model. The hybrid model allowed to make the number of considered criteria much smaller. The original set of 21 attributes regarding attractiveness and feasibility was reduced to 8 . Thus, the interpretation of the final technology assessment was simplified to analyse the values of only several variables. The application of the DEA method gave objective weight to the technology assessment criteria and eliminated arbitrariness of the criteria weights. The individual adjustment of the weights emphasised the specific features of the technology. The inclusion of the rough variables into the DEA method allowed for the possible contradiction between expert opinions. The result of the technology assessment in the form of ranges shows discrepancies in technology assessments. This can be the basis for formulating alternative balanced recommendations and creating complementary scenarios.

\section{Discussion}

Technology assessment is necessary to respond to and successfully manage technological changes. The hybrid model can be treated as a reference for complex problems of multicriteria comparative assessment made on a large set of technologies that can be characterised 


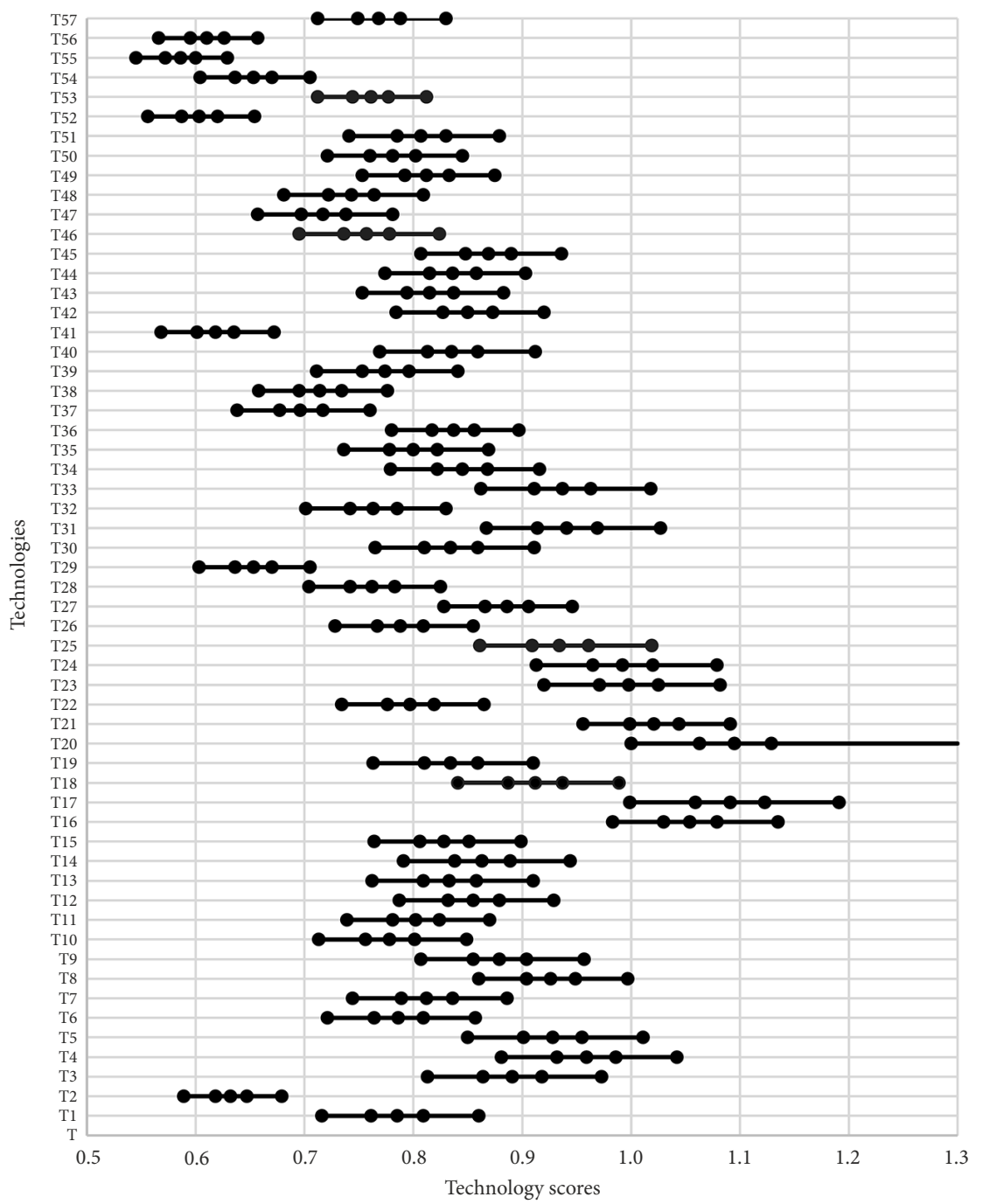

Figure 4 . Technologies assessment by the hybrid model

using a defined set of attributes that describe the technology or their interrelations as well as interactions. The obtained results regarding the use of the model documented a more objective and rational justification of the chosen technology, simplification of interpretation and better authentication of results from the perspective of decision-makers. The proposed model may facilitate the prioritisation of technologies under conditions of uncertainty, and, as a result, increase the efficiency of the use of private and public funds for research and development related to the implementation of future production solutions in line with the Industry 4.0.

The presented studies have not exhausted the further extensive research topic. The developed model should be treated as part of a wider methodology of assessment and the 
prioritisation of technology focused on prospective macro-management of technology. The authors assume the continuation of research both in the development of the methodology as well as model adaptation for specific project needs. The development of the model is related to the additional analytical capabilities of DEA, which allow determining the most important attributes for the assessed technology that affect the results achieved and simulate the impact of changes in attribute values. In addition, it is possible to identify groups of competitive technologies. The model can be adjusted through innovative approximations of rough variables and considering local and regional conditions as well as formulated needs in the tasks of developing and shaping the vision of the technological development strategy.

In the opinion of the authors, Rough Sets can be a valuable alternative to the representation of incomplete/inaccurate knowledge in relation to Fuzzy Sets, because they do not require assumptions as to the form of the membership function.

\section{Conclusions}

The paper presents an original approach to technology prioritisation based on a combination of Rough Sets and Data Envelopment Analysis. The article documented the following research task: (i) a literature review in the field of state of the art in relation to Rough Sets and DEA methods in technology assessment; (ii) a synthetic presentation of Rough Sets Theory and DEA methods, i.e. terms and models to prepare the basis for deriving the structure of the hybrid model of technology prioritisation; (iii) the development of an innovative hybrid RS-DEA model of technology prioritisation; (iv) the design of the technology assessment process using the proposed model; an example of the implementation and verification of the hybrid model of technology prioritisation.

The hybrid RS-DEA model uses: (i) the concept of reducts from the Rough Set Theory to limit the number of criteria; (ii) the approximation of the sets to model uncertainty; (iii) linear optimisation algorithms from the DEA method to objectively determine criterion weights; (iv) the relation of the efficiency from the DEA concept to build the synthetic assessment score. It is a new proposal for technology assessment that addresses the need for multifaceted and objective assessment modelling the vague valuation of criteria by individual experts. It allows to broaden the assessment and ensures a more reliable analysis of the technology rankings. Moreover, the integration into the proposed algorithm for technology assessment ensures high transparency of prioritisation procedures.

The case described in the paper demonstrated the high usefulness of the developed model in the task of technology prioritisation based on uncertain expert assessments. The obtained results allowed a more objective and rational justification of the chosen technology, simplification of interpretation and better authentication of results from the perspective of decision-makers.

In the opinion of the authors, the approach demonstrated in the paper can be extended to many other tasks related to incomplete/inaccurate knowledge about the examined objects and their attributes. 


\section{Funding}

Research was carried out in the framework of the project No. WZ/WIZ/1/2019 at the Bialystok University of Technology and financed from the subsidy granted by the Minister of Science and Higher Education.

\section{Author contributions}

J. Nazarko and E. Chodakowska were responsible for the study conception and design. E. Chodakowska performed the computation and analysis. J. Nazarko was responsible for data interpretation. J. Nazarko and E.Chodakowska discussed the results and contributed to the final manuscript.

\section{Disclosure statement}

The authors declare that not they have any competing financial, professional, or personal interests from other parties.

\section{References}

Aaltonen, M., \& Sanders, T. I. (2006). Identifying systems' new initial conditions as influence points for the future. Foresight, 8(3), 28-35. https://doi.org/10.1108/14636680610668054

Amin, G.R., \& Emrouznejad, A. (2013). A new DEA model for technology selection in the presence of ordinal data, International Journal of Advanced Manufacturing Technology, 65, 1567-1572. https://doi.org/10.1007/s00170-012-4280-3

Anderson, T. R., Hollingsworth, K., \& Inman, L. (2001). Assessing the rate of change in the enterprise database system market over time using DEA. In PICMET '01. Portland International Conference on Management of Engineering and Technology. Proceedings, Vol. 1: Book of Summaries. IEEE. https://doi.org/10.1109/PICMET.2001.951928

Atanassov, K. T. (1983, June 7-9). Intuitionistic fuzzy sets. In Proceedings of the VII ITKR's Session, Sofia, Bulgaria (reprinted in International Journal Bioautomation (2016), 20, 1-6). http://www.biomed.bas. bg/bioautomation/2016/vol_20.s1/files/20.s1_02.pdf

Atanassov, K. T. (2017). Type-1 Fuzzy Sets and Intuitionistic. Fuzzy Sets, Algorithms, 10(3), 106. https://doi.org/10.3390/a10030106

Bai, C., \& Sarkis, J. (2017). Improving green flexibility through advanced manufacturing technology investment: Modeling the decision process. International Journal of Production Economics, 188, 86-104. https://doi.org/10.1016/j.ijpe.2017.03.013

Belton, V., \& Vickers, S. P. (1993). Demystifying DEA - a visual interactive approach based on multiple criteria analysis. Journal of the Operational Research Society, 44(9), 883-896. https://doi.org/10.1057/jors.1993.157

Cagnin, C., Havas, A., \& Saritas, O. (2013). Future-oriented technology analysis: Its potential to address disruptive transformations. Technological Forecasting \& Social Change, 80(3), 379-385. https://doi.org/10.1016/j.techfore.2012.10.001 
Charnes, A., Cooper, W. W., \& Rhodes, E. (1978). Measuring the efficiency of decision-making units. European Journal of Operational Research, 2(6), 429-444. https://doi.org/10.1016/0377-2217(78)90138-8

Chodakowska, E. (2019). Hybrydowy model priorytetyzacji technologii. Oficyna Wydawnicza Politechniki Białostockiej. https://doi.org/10.24427/978-83-65596-91-8

Chodakowska, E., \& Nazarko, J. (2017a). Environmental DEA method for assessing productivity of European countries. Technological and Economic Development of Economy, 23(4), 589-607. https://doi.org/10.3846/20294913.2016.1272069

Chodakowska, E., \& Nazarko, J. (2017b). Network DEA models for evaluating couriers and messengers. Procedia Engineering, 182, 106-111. https://doi.org/10.1016/j.proeng.2017.03.130

Ciflikli, C., \& Kahya-Ozyirmidokuz, E. (2012). Enhancing product quality of a process. Industrial Management \& Data Systems, 112(8), 1181-1200. https://doi.org/10.1108/02635571211264618

Cuhls, K., Blind, K., \& Grupp, H. (2002). Innovations for our Future, Delphi '98: New foresight on science and technology. Publisher Physica-Verlag. https://doi.org/10.1007/978-3-642-57472-6

Decker, M., \& Ladikas, M. (Eds.). (2004). Bridges between science, society and policy. Technology assessment - methods and impacts. Springer-Verlag Heidelberg. https://doi.org/10.1007/978-3-662-06171-8

Doyle, J., \& Green, R. (1993). Data envelopment analysis and multiple criteria decision making. Omega, 21(6), 713-715. https://doi.org/10.1016/0305-0483(93)90013-B

Durand, T. (2003). Twelve lessons from 'Key Technologies 2005': the French technology foresight exercise. Journal of Forecasting, 22(2-3), 161-177. https://doi.org/10.1002/for.856

Ejdys, J. \& Halicka, K. (2018). Sustainable adaptation of new technology - the case of humanoids used for the care of older adults. Sustainability, 10(10), 3770. https://doi.org/10.3390/su10103770

Ejdys, J., Matuszak-Flejszman, A., Szymanski, M., Ustinovicius, L., Shevchenko, G., \& Lulewicz-Sas, A. (2016). Crucial factors for improving the ISO14001 Environmental Management System. Journal of Business Economics and Management, 17(1), 52-73. https://doi.org/10.3846/16111699.2015.1065905

Fan, J.-L., Zhang, X., Zhang, J., \& Peng, S. (2015). Efficiency evaluation of $\mathrm{CO}_{2}$ utilization technologies in China: A super-efficiency DEA analysis based on expert survey. Journal of $\mathrm{CO}_{2}$ Utilization, 11, 54-62. https://doi.org/10.1016/j.jcou.2015.01.004

Farrell, M. J. (1957). The measurement of productive efficiency. Journal of the Royal Statistical Society. Series A (General), 120(3), 253-290. https://doi.org/10.2307/2343100

Fodor, J., \& Roubens, M. (1994). Fuzzy preference modelling and multicriteria decision support. Kluwer. https://doi.org/10.1007/978-94-017-1648-2

Gordon, T. J., \& Glenn, J. C. (2004, May 13-14). Integration, comparisons, and frontier of futures research methods. In EU-US Seminar: New Technology Foresight, Forecasting \& Assessment Methods, Seville, Spain.

Greco, S., Matarazzo, B., \& Słowiński, R. (2001). Rough sets theory for multicriteria decision analysis. European Journal of Operational Research, 129(1), 1-47. https://doi.org/10.1016/S0377-2217(00)00167-3

Halicka, K. (2016). Innovative classification of methods of the future-oriented technology analysis. Technological and Economic Development of Economy, 22(4), 574-597. https://doi.org/10.3846/20294913.2016.1197164

He, Y., Pang, Y., Zhang, Q., Jiao, Z., \& Chen, Q. (2018). Comprehensive evaluation of regional clean energy development levels based on principal component analysis and rough set theory. Renewable Energy, 122, 643-653. https://doi.org/10.1016/j.renene.2018.02.028

Hemert, van P., \& Nijkamp, P. (2010). Knowledge investments, business R\&D and innovativeness of countries: A qualitative meta-analytic comparison. Technological Forecasting and Social Change, 77(3), 369-384. https://doi.org/10.1016/j.techfore.2009.08.007 
Jian, L., Liu, S., \& Liu, Y. (2010). The selection of regional key technology based on the hybrid model of grey fixed clustering and variable precision rough set. In ISTASC'10 Proceedings of the 10th WSEAS International Conference on Systems Theory and Scientific Computation (pp. 54-59).

Ju-Long, D. (1982). Control problems of grey systems. Systems and Control Letters, 1(5), 288-294. https://doi.org/10.1016/S0167-6911(82)80025-X

Karlsen, J. E., \& Karlsen, H. (2013). Classification of tools and approaches applicable in foresight studies. In M. Giaoutzi, \& B. Sapio (Eds.), Recent developments in foresight methodologies: Vol. 1. Complex networks and dynamic systems. Springer. https://doi.org/10.1007/978-1-4614-5215-7_3

Keeney, R. L., \& Raiffa, H. (1976). Decisions with multiple objectives: Preferences and value tradeoffs. John Wiley \& Sons.

Kwon, D. S., Cho, J. H., \& Sohn, S. Y. (2017). Comparison of technology efficiency for $\mathrm{CO}_{2}$ emissions reduction among European countries based on DEA with decomposed factors. Journal of Cleaner Production, 151, 109-120. https://doi.org/10.1016/j.jclepro.2017.03.065

Lai, X., Liu, J. X., \& Georgiev, G. (2016). Low carbon technology integration innovation assessment index review based on rough set theory - an evidence from construction industry in China. Journal of Cleaner Production, 126, 88-96. ttps://doi.org/10.1016/j.jclepro.2016.03.035

Lee, C., Lee, H., Seol, H., \& Park, Y. (2012). Evaluation of new service concepts using rough set theory and group analytic hierarchy process. Expert Systems with Applications, 39, 3404-3412. https://doi.org/10.1016/j.eswa.2011.09.028

Liang, X., \& Dijk, van M. P. (2016). Identification of decisive factors determining the continued use of rainwater harvesting systems for agriculture irrigation in Beijing. Water, 8(1), 7. https://doi.org/10.3390/w8010007

Lim, D.-J., Jahromi, S. R., Anderson, T. R., \& Tudorie, A.-A. (2015). Comparing technological advancement of hybrid electric vehicles (HEV) in different market segments. Technological Forecasting \& Social Change, 97, 140-153. https://doi.org/10.1016/j.techfore.2014.05.008

Liu, B. (2004). Uncertain theory: An introduction to its axiomatic foundation. Springer.

Liu, Y., Sun, C., \& Xu, S. (2013). Eco-efficiency assessment of water systems in China. Water Resource Management, 27(14), 4927-4939. https://doi.org/10.1007/s11269-013-0448-3

Łunarski, J. (2009). Zarządzenie technologiami. Ocena i doskonalenie. Oficyna Wydawnicza Politechniki Rzeszowskiej.

Luo, J.-L., \& Hu, Z.-H. (2015). Risk paradigm and risk evaluation of farmers cooperatives' technology innovation. Economic Modelling, 44, 80-85. https://doi.org/10.1016/j.econmod.2014.10.024

Magruk, A. (2011). Innovative classification of technology foresight methods. Technological and Economic Development of Economy, 17(4), 700-716. https://doi.org/10.3846/20294913.2011.649912

Magruk, A. (2017). Concept of uncertainty in relation to the foresight research. Engineering Management in Production and Services, 9(1), 46-55. https://doi.org/10.1515/emj-2017-0005

Martin, B. (1995). Foresight in science and technology. Technology Analysis and Strategic Management, 7(2), 139-168. https://doi.org/10.1080/09537329508524202

Martin, B. R. (2010), The origins of the concept of 'foresight' in science and technology: An insider's perspective. Technological Forecasting and Social Change, 77(9), 1438-1447.

https://doi.org/10.1016/j.techfore.2010.06.009

Miles, I. (2008). From futures to foresight. In L. Georghiou, J. C. Harper, M. Keenan, I. Miles, \& R. Popper (Eds.), The handbook of technology foresight. Concepts and practice. Edward Elgar Publishing Limited.

Miles, I., \& Keenan, M. (2003). Overview of methods used in foresight. The Technology Foresight for Organisers Training Course, Ankara, United Nations Industrial Development Organisation. 
Molodtsov, D. A. (1999). Soft set theory - First results. Computers \& Mathematics with Applications, 37(4), 19-31. https://doi.org/10.1016/S0898-1221(99)00056-5

Nazarko, J., \& Magruk, A. (Eds.). (2013). Kluczowe nanotechnologie w gospodarce Podlasia. Oficyna Wydawnicza Politechniki Białostockiej.

Nazarko, Ł. (2015). Technology assessment in construction sector as a strategy towards sustainability. Procedia Engineering, 122, 290-295. https://doi.org/10.1016/j.proeng.2015.10.038

Nazarko, Ł. (2017). Future-oriented technology assessment. Procedia Engineering, 182, 504-509. https://doi.org/10.1016/j.proeng.2017.03.144

Opricovic, S., \& Tzeng, G. H. (2003). Comparing DEA and MCDM Method. In Multi-Objective Programming and Goal Programming. Advances in Soft Computing 21. Springer, Heidelberg. https://doi.org/10.1007/978-3-540-36510-5_32

Pawlak, Z. (1982). Rough sets. International Journal of Computer and Information Sciences, 11(5), 341356. https://doi.org/10.1007/BF01001956

Pawlak, Z., \& Skowron, A. (2007). Rough sets: Some extensions. Information Sciences, 177, 28-40. https://doi.org/10.1016/j.ins.2006.06.006

Papagapiou, A., Mingers, J., \& Thanassoulis, E. (1997). Would you buy a used car with DEA? OR Insight, 10(1), 13-19. https://doi.org/10.1057/ori.1997.3

Pietrobelli, C., \& Puppato, F. (2016). Technology foresight and industrial strategy. Technological Forecasting and Social Change, 110, 117-125. https://doi.org/10.1016/j.techfore.2015.10.021

Popper R. (2009). Mapping foresight revealing how Europe and other world regions navigate into the future. http://www.forschungsnetzwerk.at/downloadpub/2009_efmn_mappingForesight_EU.pdf

Popper, R. (2008). How are foresight methods selected? Foresight, 10(6), 62-89. https://doi.org/10.1108/14636680810918586

Popper, R., \& Korte, W. B. (2004, May 13-14). Xtreme Euforia: combining foresight methods. In EU-US Seminar: New Technology Foresight. Forecasting \& Assessment Methods, Seville, Spain.

https://doi.org/10.14512/tatup.13.2.132

Porter, A. L. (1995). Technology assessment. Impact Assessment, 13(2), 135-151. https://doi.org/10.1080/07349165.1995.9726087

Porter, A. L. (2010). Technology foresight: types and methods. International Journal of Foresight and Innovation Policy, 6(1-3). https://doi.org/10.1504/IJFIP.2010.032664

Porter, A. L., Ashton, W. B., Clar, G., Coates, J. F., Cuhls, K., Cunningham, S. W., Ducatel, K., Duin, van der P., Georghiou, L., Gordon, T., Linstone, H., Marchau, V., Massari, G., Miles, I., Mogee, M., Salo, A., Scapolo, F., Smits, R., \& Thissen, W. [Technology Futures Analysis Methods Working Group] (2004). Technology futures analysis: Toward integration of the field and new methods. Technological Forecasting and Social Change, 71(3), 287-303. https://doi.org/10.1016/j.techfore.2003.11.004

Predki, B., Słowiński, R., Stefanowski, J., Susmaga, R., \& Wilk, S. (1998). ROSE - Software Implementation of the Rough Set Theory. In L. Polkowski \& A. Skowron (Eds.), Rough Sets and Current Trends in Computing. Lecture Notes in Artificial Intelligence, 1424, 605-608. Springer-Verlag. https://doi.org/10.1007/3-540-69115-4_85

Rohrbeck, R., \& Gemünden, H. G. (2011). Corporate foresight: Its three roles in enhancing the innovation capacity of a firm. Technological Forecasting \& Social Change, 78(2), 231-243. https://doi.org/10.1016/j.techfore.2010.06.019

Roosth, S., \& Silbey, S. (2009). Science and technology studies: From controversies to Posthumanist Social Theory. In B. S. Turner (Ed.), The New Blackwell Companion to Social Theory. Blackwell Publishing Ltd. https://doi.org/10.1002/9781444304992.ch23 
Roy, B. (1990). Wielokryterialne wspomaganie decyzji. Wydawnictwa Naukowo-Techniczne.

Sambuc, R. (1975). Fonctions $\varphi$-floues. Application 'a l'aide au diagnostic en pathologie thyroidienne (Doctoral dissertation). Université Marseille, France.

Sánchez-Torres, J. M., \& Miles, I. (2017). The role of future-oriented technology analysis in e-Government: a systematic review. European Journal of Futures Research, 5(1), 1-18. https://doi.org/10.1007/s40309-017-0131-7

Shabani, A., Saen, R. F., \& Torabipour, S. M. R. (2014). A new data envelopment analysis (DEA) model to select eco-efficient technologies in the presence of undesirable outputs. Clean Technologies and Environmental Policy, 16(3), 513-525. https://doi.org/10.1007/s10098-013-0652-0

Sharma, S., Dua, A., Singh, M., Kumar, N., \& Prakash, S. (2018). Fuzzy rough set-based energy management system for self-sustainable smart city. Renewable \& Sustainable Energy Reviews, 82, 36333644. https://doi.org/10.1016/j.rser.2017.10.099

Shiau, T.-A., \& Chuen-Yu, J.-K. (2016). Developing an indicator system for measuring the social sustainability of offshore wind power farms. Sustainability, 8(5), 470. https://doi.org/10.3390/su8050470

Shiraz, R. K., Fukuyama, H., Tavana, M., \& Caprio, Di D. (2016). An integrated data envelopment analysis and free disposal hull framework for cost-efficiency measurement using rough sets. Applied Soft Computing, 46, 204-219. https://doi.org/10.1016/j.asoc.2016.04.043

Shuai, J. J., \& Li, H. L. (2005). Using rough set and worst practice DEA in business failure prediction. In D. Ślęzak, J. Yao, J. F. Peters, W. Ziarko, \& X. Hu (Eds.), Lecture notes in computer science: Vol. 3642. Rough sets, fuzzy sets, data mining, and granular computing (pp. 503-510). Springer, Heidelberg. https://doi.org/10.1007/11548706_53

Sokolov, A., Veselitskaya, N., Carabias, V., \& Yildirim, O. (2019). Scenario-based identification of key factors for smart cities development policies. Technological Forecasting \& Social Change, 148. https://doi.org/10.1016/j.techfore.2019.119729

Srivastava, S., \& Misra, M. (2016). Assessing and forecasting technology dynamics in smartphones: a TFDEA approach. Technology Analysis \& Strategic Management, 28(7), 783-797. https://doi.org/10.1080/09537325.2016.1143094

Stewart, T. J. (1996). Relationships between DEA and MCDM. Journal of the Operational Research Society, 47(5), 654-665. https://doi.org/10.1057/jors.1996.77

Sueyoshi, T., \& Goto, M. (2014). Environmental assessment for corporate sustainability by resource utilization and technology innovation: DEA radial measurement on Japanese industrial sectors. Energy Economics, 46, 295-307. https://doi.org/10.1016/j.eneco.2014.09.021

Tohidi, G., \& Valizadeh, P. (2011). A non-radial rough DEA model. International Journal of Mathematical Modelling \& Computation, 1(4), 257-261. https://www.sid.ir/FileServer/JE/1033520110405

Voros, J. 2006. Introducing a classification framework for prospective methods. Foresight, 8(2), 43-56. https://doi.org/10.1108/14636680610656174

Wang, X., Jia, F., \& Wang, Y. (2015). Evaluation of clean coal technologies in China: Based on rough set theory. Energy \& Environment, 26(6-7), 985-995. https://doi.org/10.1260/0958-305X.26.6-7.985

Wang, C.-H., Chin, Y.-C., \& Tzeng, G.-H. (2010). Mining the R\&D innovation performance processes for high-tech firms based on rough set theory. Technovation, 30(7-8), 447-458. https://doi.org/10.1016/j.technovation.2009.11.001

Weber, K. M., Gudowsky, N., \& Aichholzer, G. (2019). Foresight and technology assessment for the Austrian parliament - Finding new ways of debating the future of industry 4.0. Futures 109, 240251. https://doi.org/10.1016/j.futures.2018.06.018

Wu, H.-Y., \& Lin, H.-Y. (2012). A hybrid approach to develop an analytical model for enhancing the service quality of e learning. Computers \& Education 58(4), 1318-1338.

https://doi.org/10.1016/j.compedu.2011.12.025 
Xu J., Li, B., \& Wu, D. (2009). Rough data envelopment analysis and its application to supply chain performance evaluation. International Journal of Production Economics 122(2), 628-638. https://doi.org/10.1016/j.ijpe.2009.06.026

Yu, P., \& Lee, J. H. (2013). A hybrid approach using two-level SOM and combined AHP rating and AHP/DEA-AR method for selecting optimal promising emerging technology. Expert System with Applications 40, 300-314. https://doi.org/10.1016/j.eswa.2012.07.043

Zadeh, L. A. (1965). Fuzzy sets, Information and Control 8(3), 338-353. https://doi.org/10.1016/S0019-9958(65)90241-X

Zavadskas, E. K., Antucheviciene, J. \& Kar, S. (2019). Multi-Objective and Multi-Attribute Optimization for Sustainable Development Decision Aiding. Sustainability 11, 3069. https://doi.org/10.3390/su11113069

Zavadskas, E. K., \& Turskis, Z. (2011). Multiple Criteria Decision Making (MCDM) methods in economics: An overview. Technological and Economic Development of Economy 17(2), 397-427. https://doi.org/10.3846/20294913.2011.593291

Zeng, X. T., Huang, G. H., Yang, X. L., Wang, X., Fu, H., Li, Y.P., \& Li, Z. (2016). A developed fuzzystochastic optimization for coordinating human activity and eco-environmental protection in a regional wetland ecosystem under uncertainties. Ecological Engineering, 97, 207-230.

https://doi.org/10.1016/j.ecoleng.2016.09.002 